\title{
COMMENT
}

\section{GARY SNYDER}

As a poet I hold the most archaic values on earth. They go back to the Paleolithic: the fertility of the soil, the magic of animals. The power-vision in solitude, the terrifying initiation and rebirth, the love and ecstasy of the damned, the common work of the tribe.

There is a level of mind which must be distinguished from the purely ecstatic, where the most immediate and personal perceptions fuse with the archetypal and ritual relationships of human society to the universe. Poetry made from here is not "automatic," but it is often effortless; and it does not exclude the pleasure of occasional intellectual ingenuity and allusion. My best poems flow from such a state; they have a tendency toward exploring the architecture of consciousness. 